\title{
Sociolinguística e sua interface com o ensino: os marcadores conversacionais [é] e [tá] na oralidade de adolescentes de escolas públicas
}

\author{
Sociolinguistics and its interface with teaching: the conversational markers [é] \\ and [tá] in the orality of adolescents from public schools
}

\author{
Elza Sabino da Silva Bueno ${ }^{1}$ \\ Universidade Estadual de Mato Grosso do Sul \\ Lucas de Souza Machado ${ }^{2}$ \\ Universidade Estadual de Mato Grosso do Sul \\ Neide Araújo Castilho Teno ${ }^{3}$ \\ Universidade Estadual de Mato Grosso do Sul
}

\begin{abstract}
- RESUMO: Pesquisadores da área de linguagem tem voltado seus estudos para entender fenômenos que ocorre na fala reconhecendo seus valores sociais e sua relação com o ensino. A presente pesquisa vincula se na área dos estudos da sociolinguística variacionista com a intenção de refletir sobre o uso dos marcadores conversacionais [é] e [tá] na oralidade de adolescentes de Dourados-MS, no sentido de verificar o seu efeito de sentido no discurso desses jovens. Para o desenvolvimento do estudo utilizamos como aporte teórico de investigação do uso dos marcadores estudos realizados por: Bagno (2003/2012), BortoniRicardo (2004), Bueno e Silva (2012), Urbano (2010), Preti (2010), Marcuschi (2011), Tarallo (2007), e outros. Em relação ao uso dos marcadores [é] e [tá] foram analisados cento e quarenta e dois fenômenos linguísticos oriundos da fala espontânea. Sobre os resultados obtidos na pesquisa, é possível inferir que os falantes, alunos de diferentes faixas etárias se valem dos marcadores como recursos discursivos para dar coerência ao texto falado, com vistas a facilitar a comunicação.
\end{abstract}

- PALAVRAS-CHAVE: Oralidade; Ensino; Marcadores conversacionais; Sociolinguística variacionista.

- ABSTRACT: The meanings of a word happen in and through the enunciation event whereby a word, a term, an expression works by naming something, a person, or simply articulating itself in specific ways in a text. Our objective here is to observe the semantic / enunciative functioning of the word / term baderna that starts to function in the lexicon that composes the Portuguese language of Brazil from a certain moment in history, constituting a meaning that moves the term from the place of a proper personal name for naming negative

\footnotetext{
${ }^{1}$ Doutora em Letras pela Universidade Estadual Paulista-FCL-UNESP/Assis-SP. Docente da graduação e da pósgraduação da Universidade Estadual de Mato Grosso do Sul - UEMS/Dourados-MS. É Coordenadora adjunta do Mestrado Profissional em Letras - Profletras e coordena o projeto de pesquisa "Apoio à qualificação docente: Profletras em MS", Colaboradora no projeto de pesquisa "Memorias de professores: diálogos sobre o letramento e o ensino de língua portuguesa-Etapa II.E-mail: elza@uems.br.

${ }^{2}$ Mestrando do Programa de Pós-Graduação em Letras da Universidade Estadual de Mato Grosso do Sul UEMS/Campo Grande. Professor da Rede Pública de Ensino de Campo Grande/MS.E-mail: elza@uems.br.

${ }^{3}$ Doutora em Educação/Letras. Docente Sênior do Programa de Mestrado Profissional em Letras-PROFLETRAS, e do Programa de Mestrado Acadêmico em Letras da Universidade Estadual de Mato Grosso do Sul UEMS/Dourados. /Campo Grande. Colaboradora do projeto de pesquisa "Apoio à Qualificação Docente: PROFLETRAS em Mato Grosso do Sul" financiado com recurso da FUNDECT. Coordenadora do projeto de pesquisa "Memorias de professores: diálogos sobre o letramento e o ensino de língua portuguesa-Etapa II. Email: cteno@uol.com.br.
} 
behavior at certain times. To this end, we will use the theory of semantics of event of Guimarães (2002) as the theoretical and methodological direction for our analyzes of the word / term baderna in the texts selected for this work.

- KEYWORDS: Semantics; Event; Baderna.

\section{Introdução}

Ao iniciar um trabalho acerca da língua, mais precisamente com a fala de adolescentes, trabalhamos o modo de produção desta fala, como ela se realiza e quais elementos linguísticos que contribuem para essa realização. Sendo assim, os marcadores conversacionais precisam ser levados em conta, uma vez que marcam sequências de fala e estabelecem a organização dos conteúdos do discurso produzido oralmente.

Nesse sentido, os marcadores conversacionais, enquanto conectivos textuais de fala, atuam como ferramentas para que o falante torne sua produção oral mais coerente. Para melhor exemplificar, Marcuschi (2011) subdivide marcadores conversacionais em três classes distintas: os verbais, os não verbais e os suprassegmentais. Os verbais formam uma classe de palavras desprestigiada que não agrega, ao conteúdo da fala, nada de novo, entretanto, esta classe situa e organiza a fala. Os não verbais, por sua vez, dizem respeito à expressão facial, ao gesto e a quaisquer posturas físicas seja, riso, mexida de cabeça, gestos com as mãos entre outras. E os recursos suprassegmentais são as pausas realizadas na oralidade e estão relacionados à voz do interlocutor, para uma melhor compreensão da mensagem a ser transmitida.

Compreendendo que a língua é um organismo vivo e propício a mudanças e variações no tempo e no espaço, pesquisamos e analisamos a presença de fenômenos linguísticos característicos da oralidade como os marcadores [é] e [tá] que funcionam como elementos para conectar e estruturar a fala de adolescentes alfabetizados, residentes no município de Dourados-MS, para perceber o uso e a intencionalidade desses fenômenos e contribuir com o ensino de língua portuguesa no viés dos estudos sociolinguísticos variacionistas.

Diante do exposto, propomo-nos, com esta pesquisa, analisar os marcadores conversacionais [é] e [tá] no processo de produção da fala, no sentido de verificar o efeito de sentido causado por esses conectivos na fala de adolescentes de escolas públicas de Dourados-MS, além de verificar a forma como esses marcadores são usados e em quais situações reais de comunicação eles são usados para dar clareza à comunicação.

Ressaltamos que o presente estudo analisa a fala de 40 informantes, 20 do sexo masculino e 20 do sexo feminino, com faixa etária entre 12 a 18 anos, de 2 escolas no município de Dourados-MS e, consiste em uma das atividades relacionadas a um estudo maior intitulado: "Variação linguística: simplificação das formas verbais ser, estar, ir e ficar na oralidade de adolescentes em Dourados-MS".

Utilizamos como aporte teórico dessa pesquisa os estudos de Marcuschi (2011), Urbano (2010), Preti (2010), Bortoni-Ricardo (2004), entre outros estudiosos da linguagem que se fizeram necessários.

A seguir destacamos a importância dos marcadores conversacionais e seu efeito de sentido no discurso oral dialogado a fim de propor maior clareza para esta pesquisa. 


\section{A importância dos marcadores conversacionais}

Os marcadores conversacionais ou articuladores são próprios da fala, todavia, às vezes, influenciam a escrita. São, de acordo com Marcuschi (2011, p. 282), elementos que contribuem para que o texto falado tenha maior clareza, coesão e coerência. São eles que promovem as articulações verbal, cognitiva e interacional no texto falado. De acordo com Urbano (2010 p. 99), há marcadores conversacionais de nível linguístico e não linguístico, sendo:

i. Os linguísticos: verbais (lexicados (sabe?); não lexicados (ahn)); prosódicos (pausas, alongamentos).

Os marcadores verbais estão categorizados em classes: simples (sabe?); complexos (quer dizer, no fundo); oracionais (eu tenho a impressão de que) e combinados (mas acho que).

ii. Não linguísticos (olhar, risos, gestos, entre outros) $)^{4}$.

Atemo-nos na presente pesquisa apenas aos marcadores [é] e [tá], por serem de nível linguístico e serão explorados acerca de seu efeito de sentido nas análises do material que compõe o corpus desta investigação.

Desta forma, é possível afirmar que os marcadores conversacionais, os articuladores de fala, responsáveis pela coesão e coerência do texto falado são imprescindíveis para o processo de compreensão da mensagem. $\mathrm{O}$ interlocutor organiza o pensamento a partir da utilização de marcadores pelo seu locutor.

De acordo com Botler e Suassuna (2016, p.86) a oralidade é "uma prática social com objetivos de interação definidos, que se manifesta em diferentes gêneros textuais por meios sonoros. Ela pode variar entre formas mais ou menos formais, a depender do contexto de uso" da língua em situações reais de comunicação linguística. Sendo assim, justificamos a opção por uma entrevista Sociolinguística de caráter informal, a fim de preservar a maneira menos formal de uso da língua. Os entrevistados para esta pesquisa são alunos, adolescentes, com idade entre 12 a 18 anos, moradores na periferia do município de Dourados-MS e estudantes de escola públicas.

\subsection{Oralidade e ensino de língua portuguesa em sala de aula}

É natural que alunos, adolescentes, utilizem marcadores conversacionais no dia a dia, cabe então, à escola e ao professor promover a clareza do momento e do contexto de uso de determinadas variedades linguísticas, no sentido de tratar a linguagem oral com maior importância no processo de ensino e aprendizagem de língua portuguesa em sala de aula. Desta forma, discutimos e refletimos sobre o uso da oralidade em sala de aula e a contribuição dos estudos sociolinguísticos variacionistas para a clareza de comportamentos linguísticos diante do uso real da língua. Essa pesquisa acerca da oralidade no português brasileiro está vinculada à aprendizagem de língua portuguesa, uma vez que o uso da linguagem oral de adolescentes alfabetizados em Dourados/MS, informantes sujeitos de nossa pesquisa, e o tratamento dessa linguagem oral, utilizada

\footnotetext{
${ }^{4}$ Para visualização dos aspectos dos marcadores conversacionais descritos sugerimos a leitura do livro: URBANO, Hudinilson. Marcadores conversacionais. In PRETI, Dino. Análise de textos orais. São Paulo-SP: Humanitas, 2010 p.93-116.
} 
por eles, dentro e fora do ambiente escolar estão associados ao processo de aprendizagem e ao uso da língua em situações reais de comunicação linguística.

Partindo dessa associação e considerando o que afirma Bagno (2012, p.194) de que: "é na língua falada pelas gerações mais jovens que podemos localizar indícios bem claros da mudança linguística", o trabalho com linguagem oral no ensino e na aprendizagem de língua portuguesa se torna de suma importância para a compreensão de diferentes fenômenos linguísticos. Para aclarar ainda mais os nossos pensamentos acerca da língua, os PCN (Parâmetros Curriculares Nacionais) (BRASIL, 1998) salientam que: "ensinar língua oral deve significar para a escola possibilitar acesso a usos da linguagem mais formalizados e convencionais, que exijam controle mais consciente e voluntário da enunciação" (p. 67). Sendo assim, de acordo com os PCN (BRASIL, 1998, p.25):

Cabe à escola ensinar o aluno a utilizar a linguagem oral no planejamento e realização de apresentações públicas: realização de entrevistas, debates, seminários, apresentações teatrais etc. Trata-se de propor situações didáticas nas quais essas atividades façam sentido de fato, pois é descabido treinar um nível mais formal da fala, tomado como mais apropriado para todas as situações. A aprendizagem de procedimentos apropriados de fala e de escuta, em contextos públicos, dificilmente ocorrerá, se a escola não tomar para si a tarefa de promovê-la.

O ensino da produção oral e sua importância refletem, para Marote e Ferro (1994), a possibilidade de trabalhar aspectos fundamentais ao ato comunicativo como entonação, dicção, gesto, postura, turnos de conversação, além de perceber as variedades linguísticas e tomar conhecimento de seus respectivos valores e usos na sociedade.

Neste sentido, a escola enquanto instituição atenta ao processo de ensino e aprendizagem e o professor de língua portuguesa precisam ter em conta que o objetivo, tanto da escola como instituição pedagógica e do professor, é preparar o aluno para as mais diversas situações de fala (escrita/oral), contribuindo com a cidadania e com o aspecto social do aluno, no sentido de "levar os alunos a ultrapassar as formas de produção oral cotidiana para confrontá-las com outras formas mais institucionais" externas à prática habitual, cotidiana, Schneuwly e Dolz (2004, p. 147). Somando a nossa afirmação, Antunes (2003, p, 110) salienta que o ensino de português, e seus programas de estudos precisamente, têm a função de: "ampliar a competência do aluno para o exercício cada vez mais pleno, mais fluente e interessante da fala e da escrita, incluindo escuta e leitura", além de desmistificar a ideia de que a linguagem popular e a maneira individual do falante ao se expressar, é incorreta, é feia e pobre.

A seguir fez-se necessário aclarar a trajetória dos estudos variacionistas.

\subsection{A sociolinguística e sua importância para o ensino e aprendizagem de língua portuguesa em sala de aula}

Os entrevistados da pesquisa são alunos, adolescentes, moradores no munícipio de Dourados-MS, assim, consideramos pertinente o papel da escola, o ensino e a aprendizagem de língua, haja vista que a pesquisa auxilia a prática de uso da língua no 
ambiente escolar e/ou fora dele, sendo que a escola e a sala de aula também são comunidades de fala.

Com nossa investigação sobre a língua falada, em especial a utilização dos marcadores conversacionais: [é] e [tá], por adolescentes com o aporte teórico de estudiosos da Sociolinguística Variacionista e ensino-aprendizagem, podemos inferir que é possível a escola ensinar a norma padrão sem desprestigiar a norma não padrão, "é preciso substituir definitivamente a ideia de uso de certo ou errado pela de uso do adequado ou não adequado" (TRAVAGLIA, 2009, p.66).

Desta forma, a partir dos usos orais dos investigados de nossa pesquisa, pretendemos refletir sobre a valorização da oralidade em sala de aula, com vistas a colaborar com o professor na sua metodologia e na sua prática pedagógica em sala de aula.

Ao tratar do processo de ensino aprendizagem, deve-se incluir, especialmente na formação do licenciado em língua materna, a conscientização do ensino da variedade, conhecimento da fala do aprendiz e suas variedades, além de eliminar o preconceito de que o professor fala "certo" e o aluno fala "errado" (GORSKI e COELHO, 2006), respeitando o que nos sugere o PCN de Língua Portuguesa (BRASIL, 1998, p. 29) ao ressaltarem que:

\begin{abstract}
A variação é constitutiva das línguas humanas, ocorrendo em todos os níveis. Ela sempre existiu e sempre existirá, independentemente de qualquer ação normativa. Assim, quando se fala em Língua Portuguesa. está se falando de uma unidade que se constitui de muitas variedades.
\end{abstract}

No tocante ao papel do professor e às aulas de língua portuguesa, Machado e Bueno (2017, p. 1.217), declaram que:

\begin{abstract}
Alunos e professores, por meio de formação e investigações sérias precisam refletir, perceber e compreender os diversos fenômenos linguísticos, contrários à língua padronizada. E compreender, que o aluno não é uma folha em branco, é necessário o respeito aos saberes, além de uma metodologia que respeite as diversidades naturais e comuns às línguas vivas em transformação.
\end{abstract}

Bueno e Melo apud Bueno e Pressotto, (2011, p.28), a respeito desse assunto, ressaltam que: "a não valorização da oralidade não capacita o aluno para o uso da língua que deve atender todas as convenções sociais". Diante dessa afirmativa de Bueno podemos inferir a importância da língua falada no processo da comunicação e a necessidade de conhecer o sistema linguístico de nossa língua para que possamos nos comunicar com precisão e sermos compreendidos no momento da interação linguística. "A escola deve iniciar o aluno valorizando seus hábitos culturais, levando-o a adquirir novas habilidades" (CASTILHO, 1998, p.21).

Ainda sobre esse assunto, Luft (1993, p.30) assevera que é papel da escola: "ir aumentando a capacidade comunicativa dos alunos, trabalhar muito com a língua, melhorando sempre mais e tornando mais produtivo o manejo desse instrumento", haja vista que o aluno já fala a sua língua materna. Como o aluno já é falante de sua língua materna e cabe à escola ampliar esses conhecimentos para que ele possa comunicar com desenvoltura, usando os recursos linguísticos que a própria língua portuguesa oferece.

Uma das contribuições dos estudos sociolinguísticos variacionistas é justamente promover em sala de aula a valorização e respeito à língua falada, construindo novos saberes no repertório do aluno, isto é, escola, professor e ensino precisam contribuir para que o aluno possa aceitar as diferenças como algo positivo e

Traços de Linguagem, Cáceres, v. 4, n. 2, p. 81-90, 2020. 
encarar o português brasileiro como ele realmente é, isto é, heterogêneo, uma vez que "A escola é um espaço de interação social onde práticas sociais de linguagem acontecem [...] assumindo características bastante específicas em função de sua finalidade: o ensino" (BRASIL, 1998, p.22).

Diante do exposto, é impossível ignorar a língua falada e os aspectos culturais do alunado, não é errado ensinar a variedade padrão, "o problema, é apresentar a chamada variedade culta ou padrão como a única possível "correta" no uso da língua" (TRAVAGLIA 2009, p.64). E, por fim, é fundamental ter em conta que cabe ao professor: "planejar, implementar e dirigir as atividades didáticas, com o objetivo de desencadear, apoiar e orientar o esforço de ação e reflexão do aluno, procurando garantir aprendizagem efetiva" (BRASIL, 1998, p.22). Sendo assim, defendemos que o respeito à variação linguística e ao social do aluno precisa estar em sintonia com um ensino respeitador e precisa a todo instante tanger o trabalho pedagógico do docente, Bortoni-Ricardo (2004).

\section{Metodologia}

Em um primeiro momento realizou-se leituras e fichamentos das obras que foram pesquisadas e que fundamentam nosso estudo. Depois se procedeu à tabulação e análise da fala dos adolescentes alfabetizados do município de Dourados-MS com relação ao emprego dos marcadores [é] e [tá] para verificar seu uso e efeitos de sentido na oralidade desses alunos.

Em um segundo momento, verificou-se de que forma a disciplina de língua portuguesa na escola trata o uso dos marcadores conversacionais, esses fenômenos linguísticos pertencentes à modalidade oral da língua em sala de aula.

Ressaltamos que organizamos as 40 entrevistas em 8 células linguísticas, isto é, em 8 grupos linguísticos que dão maior clareza às análises sociolinguísticas, de acordo com Tarallo (2007). Vejamos a seguir as células organizadas para a elaboração do estudo.

\begin{tabular}{|c|c|c|c|c|}
\hline \multicolumn{5}{|c|}{ Figura 1 - Do perfil dos alunos sujeitos da pesquisa } \\
\hline CÉLULA & GÊNERO & ESCOLA & $\begin{array}{c}\text { NÍVEL DE } \\
\text { ESCOLARIDADE }\end{array}$ & $\begin{array}{c}\text { FAIXA } \\
\text { ETÁRIA }\end{array}$ \\
\hline $1^{a}-$ & Masculino & A & Ensino Fundamental & $12-15$ \\
\hline $2^{\mathrm{a}}-$ & Feminino & A & Ensino Fundamental & $12-15$ \\
\hline $3^{\mathbf{a}}-$ & Masculino & A & Ensino Médio & $16-18$ \\
\hline $4^{\mathrm{a}}-$ & Feminino & A & Ensino Médio & $16-18$ \\
\hline $5^{a}-$ & Masculino & B & Ensino Fundamental & $12-15$ \\
\hline $6^{\mathrm{a}-}$ & Feminino & B & Ensino Fundamental & $12-15$ \\
\hline $7^{\mathrm{a}}-$ & Masculino & B & Ensino Médio & $16-18$ \\
\hline $8^{a}-$ & Feminino & B & Ensino Médio & 16- 18 \\
\hline \multicolumn{5}{|c|}{ Total $=40$ informantes } \\
\hline
\end{tabular}

A escolha da comunidade de fala ${ }^{5}$ foi intencional, elegemos duas escolas estaduais localizadas na cidade de Dourados-MS, que ofertam ensino fundamental e médio. Dentre as 18 escolas estaduais do município de Dourados-MS, selecionamos

\footnotetext{
${ }^{5}$ Comunidade de fala é o termo utilizado por Tarallo (2007) para designar o grupo de falantes estudados, o grupo de informantes da pesquisa.
} 
duas, cujo critério de escolha foi a nota do IDEB (Índice de Desenvolvimento da Educação Básica), observada em 2015. Optamos por verificar as notas do IDEB a fim de sermos democráticos e termos duas escolas com contrastes educacionais diferentes para analisar. Assim, elegemos uma escola estadual com nota inferior a 5,0 no IDEB e uma superior a 6,5 de nota obtida no IDEB.

Deste modo, conduzimos a presente pesquisa para o estudo desses fenômenos linguísticos que caracterizam e contribuem para a formação do português brasileiro em Dourados-MS.

\section{Análise dos dados e discussão dos resultados}

Com os resultados dessa pesquisa sobre os marcadores conversacionais ou conectivos [é] e [tá] esperamos contribuir para o entendimento científico e tecnológico no âmbito do ensino em sala de aula, além de mostrar a relevância acerca dos estudos sobre o português brasileiro e sobre o processo de variação e mudança linguística que são fatores inerentes às línguas vivas e em processo de transformação no tempo e no espaço, para atender às necessidades comunicacionais do falante.

Para a constituição do corpus do estudo foram realizadas entrevistas com os sujeitos da pesquisa, em seguida as entrevistas realizadas que serviram de material investigativo para a análise dos dados foram transcritas a partir das normas do projeto NURC/SP (Projeto Norma Urbana Culta/ SP), adaptadas pelo Professor Dr. Pedro Caruso (UNESP/Assis).

As entrevistas foram realizadas dentro das escolas selecionadas, com autorização da coordenação pedagógica e dos pais dos respectivos alunos entrevistados e, para efeito de análise, destacamos trechos em que aparecem os marcadores pesquisados.

A seguir apresentamos as análises realizadas nesse estudo, com os marcadores discursivos [é] e [tá]. Vejamos cada um desses marcadores e os percentuais de uso.

O marcador discursivo é foi utilizado 120 vezes, nas 8 células linguísticas pesquisadas e é sempre empregado na oralidade dos entrevistados, como forma de marcar o discurso.

A forma verbal é, $3^{\text {a }}$ pessoa do singular no presente do indicativo, foi utilizada como elemento que dá maior clareza e coerência à fala, para realçar os efeitos de sentido na fala dos sujeitos da pesquisa. O aluno se vale do marcador para organizar a própria fala, é um mecanismo utilizado pelo falante para aclarar a mensagem transmitida, estabelecer sentido e sequência, uma forma do raciocínio não se perder. Vejamos o exemplo a seguir:

1. "i daí nu finau du filme, é, eli... eli sai sauvanu todu mundu, purque tipu foi todu mundu baliadu, todu mundu ferradu lá" (EM/16/F/EV/2) ${ }^{6}$.

\footnotetext{
${ }^{6}$ As informações dos adolescentes entrevistados obedecem a seguinte ordem: a sigla que representa o informante (a letra inicial do nome e sobrenome, exemplo: BE); a faixa etária (12 -15; 16-18, exemplo: 18), a sigla que representa o gênero ( $M$, quando masculino; $F$, quando feminino, exemplo: $M$ ), a sigla que representa a escola (EV; ER, exemplo: EV), a abreviação que representa grau de escolaridade (1, Ensino Fundamental; 2, Ensino Médio, exemplo: 2). Desta forma temos: (BE/18/M/EV/2).
}

Traços de Linguagem, Cáceres, v. 4, n. 2, p. 81-90, 2020. 
De acordo com Castilho (2016), o marcador discursivo /é.../ é pragmático ou interpessoal (orientado para o interlocutor) e assim como o /tá.../ está colocado como medial na posição do enunciado, para realçar o efeito de sentido no discurso dos adolescentes.

Percebam que no trecho da fala do informante, o primeiro é estabelece um suporte que permite pausar a fala para não perder a sequência lógica do pensamento. Após a pausa causada pelo uso do é o informante alonga a vogal [i] "eli... eli sai [...]", isto ocorre para que o interlocutor não se perca no raciocínio o locutor/informante e emprega o marcador em questão no meio de pausas e, logo após, prossegue com a mensagem, normalmente.

Vejamos o que ocorre com o marcador tá:

O marcador discursivo tá, apareceu 22 vezes, em 6 células linguísticas, também foi empregado na oralidade dos entrevistados, assim como a variante é. Vejamos o exemplo:

2. "eli recupera a consciência deli qui foi lá nu planeta deli incontrô a chefa deli lá, qui criô elis, levô um tapa... u rostu deli ficô vermeliu... aí continuanu, tá, tá, tá, tá, tá... levô u tapa, tá... aí chegô uma navi, uma navi mãi qui us otus carrus, us otus transformis ía derrubá num cunsiguiram" $(\mathrm{SG} / 13 / \mathrm{M} / \mathrm{ER} / 1)$.

O informante, do trecho exemplificador, pretende, com a utilização do marcador tá, pausar a mensagem, porém o locutor organiza seu pensamento a partir do marcador discursivo. Vejamos, é como se ele estivesse selecionando mentalmente as palavras a serem empregas para dar continuidade ao processo de conversação e à mensagem que pretende transmitir. Embora a sequência do marcador tá assemelha-se a uma onomatopeia está não foi a intenção do falante. A intenção dele foi simplesmente repetir o tá a fim de enquanto repete ir organizando o pensamento. De qualquer forma o próximo tá em "tá... aí chegô" ilustra com maior facilidade a intenção de organizar a fala e o raciocínio.

Vejamos a figura a seguir que traz o uso dos marcadores [é] e [tá].

Figura 2 - Totais de uso dos marcadores é e tá distribuídos pelas células pesquisadas

\begin{tabular}{|c|c|c|c|c|c|c|c|c|}
\hline $\begin{array}{c}\text { Fenômenos } \\
\text { aparentes }\end{array}$ & $\begin{array}{c}\text { Célula } \\
\mathbf{1}\end{array}$ & $\begin{array}{c}\text { Célula } \\
\mathbf{2}\end{array}$ & $\begin{array}{c}\text { Célula } \\
\mathbf{3}\end{array}$ & $\begin{array}{c}\text { Célula } \\
\mathbf{4}\end{array}$ & $\begin{array}{c}\text { Célula } \\
\mathbf{5}\end{array}$ & $\begin{array}{c}\text { Célula } \\
\mathbf{6}\end{array}$ & $\begin{array}{c}\text { Célula } \\
\mathbf{7}\end{array}$ & $\begin{array}{c}\text { Célula } \\
\mathbf{8}\end{array}$ \\
\hline $\begin{array}{c}\text { É (como marcador } \\
\text { discursivo) }\end{array}$ & 5 & 26 & 17 & 10 & 10 & 7 & 16 & 29 \\
\hline $\begin{array}{c}\text { TÁ (como marcador } \\
\text { discursivo) }\end{array}$ & 4 & 3 & 0 & 2 & 6 & 0 & 4 & 3 \\
\hline
\end{tabular}

Vale ressaltar que as transcrições apresentadas são respectivamente da $4^{\mathrm{a}} \mathrm{e}$

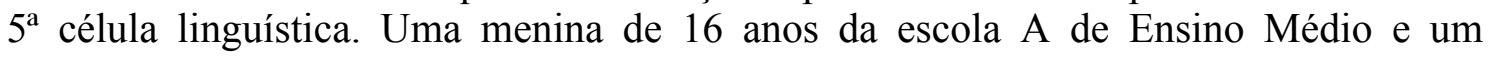
menino de 13 anos da escola B do Ensino Fundamental. Todos os informantes analisados utilizam os marcadores lexicados para a mesma finalidade a de organizar o pensamento de forma coerente e dar sequência ao discurso a fim de obter sentido. Esses marcadores são próprios do discurso e não necessariamente influenciarão no texto escrito. 


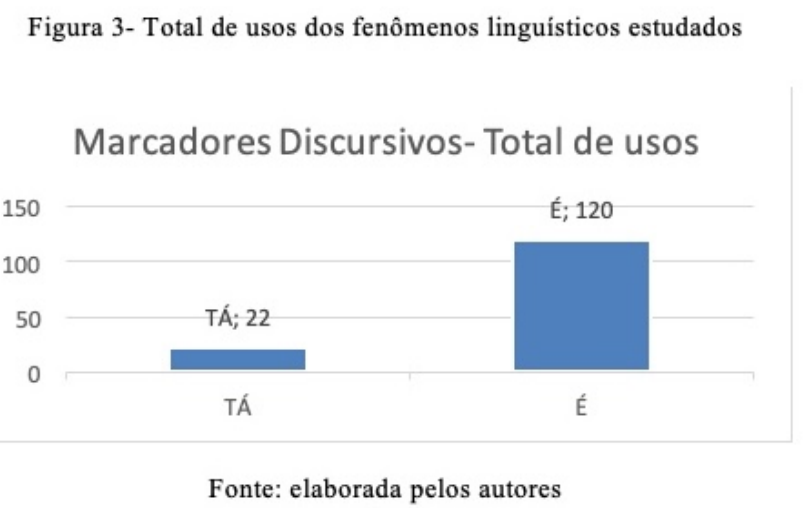

Evidenciamos em nosso trabalho que alunos de idades diferentes se valem do uso dos marcadores discursivos, recursos argumentativos para dar coerência e coesão ao texto falado e por estes recursos serem extremamente frequentes na oralidade, os resultados dessa pesquisa devem ser levados em conta, a fim de que estes marcadores discursivos não sejam coibidos em sala de aula, mas que o aluno aprenda que são recursos que a própria língua oferece e que têm sentido e motivação para serem usados na fala.

\section{Considerações finais}

A partir desta pesquisa descrevemos a língua portuguesa viva e contribuímos com o entendimento científico e tecnológico no âmbito do ensino e aprendizagem em sala de aula, além de destacar a relevância dos estudos sobre o português brasileiro, a fala e suas diferentes variedades.

Diante do exposto, podemos ressaltar que a pesquisa tem um caráter contributivo na metodologia do professor em sala de aula e no processo de ensino de língua objetivando unir a ciência linguística com o ensino de língua materna em sala de aula a final a oralidade também é parte integrante do ensino e suas características são pertinentes para o processo de ensino-aprendizagem.

\section{REFERÊNCIAS}

ANTUNES, I. Aula de Português: encontro \& interação. São Paulo: Parábola Editorial, 2003.

BAGNO, M. Gramática Pedagógica do Português Brasileiro. São Paulo: Parábola, 2012.

BORTONI-RICARDO, S. M. Educação em língua materna: a sociolinguística na sala de aula. São Paulo: Parábola, 2004.

BRASIL. Parâmetros Curriculares Nacionais (PCN). Língua Portuguesa. Ensino Fundamental. Terceiro e quarto ciclos. Brasília: MEC/SEF, 1998.

BUENO, E. S. da S.; MELO, R. B. dos S. Marcas da oralidade em textos de alunos do ensino fundamental e médio de escola pública. In BUENO, E. S. da S.. PRESSOTTO, P. H.. Estudos linguísticos e Literários I: um olhar da lato sensu. Dourados/MS: Editora UEMS. 2011. 
BUENO, E. S. da S.; SILVA, R V. da. Contribuições da pesquisa sociolinguística ao ensino da língua portuguesa no Brasil. Edição atual - Anais do SIELP. Volume 2, Número 1. Uberlândia: EDUFU, 2012.

CASTILHO, A. T. de. A língua falada no ensino de português. São Paulo: Contexto. 1998.

CAStilHO, A. T. de. Nova Gramática do Português Brasileiro. São Paulo: Contexto. 2016.

GÖRSKI, E. M. e COELHO. I. L. Sociolinguística e Ensino: contribuições para a formação do professor de língua. Florianópolis: Editora UFSC. 2006.

IDEB. Índice de Desenvolvimento da Educação Básica. 2017. Disponível em < http://ideb.inep.gov.br/> Acessado em: 03 de agosto de 2017.

LUFT, C. P. Lingua e Liberdade. São Paulo: Ática. 1993.

MACHADO, L. de S.; BUENO, E. S. da S. Reflexão diacrônica acerca do clítico /se/ e sua manifestação na produção textual de alunos do ensino fundamental. Revista Philologus, v. 67, p. 1212-1233, 2017.

MARCUSCHI, L. A. Marcadores conversacionais no português brasileiro: formas, posições e funções. In.: CASTILHO, A. T. de (org.). Português culto falado no Brasil. Campinas: Editora UNICAMP, 2011.

MAROTE, J. T.; FERRO, G. Didática da língua portuguesa. $11^{\mathrm{a}}$ ed. São Paulo: Ática, 1994.

PRETI, D. Análise de textos orais. São Paulo-SP: Humanitas, 2010.

SCHENEUWLY, B. DOLZ, J. Gêneros Orais e Escritos na Escola. 1. ed. CampinasSP: Mercado de Letras, 2004.

TARALLO, F. A pesquisa sociolinguística. $7^{\mathrm{a}}$ ed. São Paulo: Ática, 2007.

TRAVAGLIA, L. C. Gramática e Interação: uma proposta para ensino no $1^{\circ}$ e $2^{\circ}$ graus. São Paulo: Cortez. 2009.

URBANO, H. Marcadores conversacionais. In PRETI, D. Análise de textos orais. São Paulo-SP: Humanitas, 2010.

Recebido em: junho de 2020. Aprovado em: setembro de 2020.

\section{Como citar este trabalho:}

BUENO, E. S. da S.; MACHADO, L. de S.; TENO, N. A. C. Sociolinguística e sua interface com o ensino: os marcadores conversacionais [é] e [tá] na oralidade de adolescentes de escolas públicas. Traços de Linguagem. v. 4, n. 2, p. 81-90, 2020. 